\title{
Study on Lyric Translation
}

\author{
Hu Yuanyuan \\ School of Foreign Languages, Yan'an University \\ Yan'an, China \\ Email: hongseyanan@126.com
}

\begin{abstract}
This thesis is to probe on the specialties and functions of lyric translation by analyzing the history of lyric translation and the characteristics of lyrics. Lyric translation needs not only artistic skills but also ideological insights. Apart from culture exchange, the most important purpose for lyric translation is to transmit the original philosophical ideas by achieving the transmission of original sentiment and flavor to promote frequent culture communication and advocate a harmonious world.
\end{abstract}

Keywords_Lyric translation; Poetics; Musicality; Philosophy; Culture

\section{A REVIEW OF LYRIC TRANSLATION}

Lyric translation consists of that from Chinese to foreign and vice versa. The former actually covers a long period of time if we regard poems as lyrics which is in fact the truth. From The Book of Historical Documents in ancient times till Lu Xun's A Madman's Diary in twentieth century, works are called Chinese Classics [1]. Among these classics, poetry collections like The Book of Song, Elegies of the South, Han Yue Fu, Yu Tai Xin Yong and The Poetry of the High Tang include beautiful poems popular among common people. Many of these poems which are used for singing in traditional Chinese history are translated and retranslated repeatedly by translators at home and abroad. In nineteenth century and the earlier twentieth century, a large number of English missionaries and diplomats, such as James Legge, Sir John Francis Davis, Edward Harper Parke, Herbert Allen Giles, William John Bain Brigge Fletcher, and so on, translated The Book of Poems and Tang poems into English. From twentieth century on, English sinologist Arthur Waley, German writer Hans Bethge, American poet Ezra Pound, American translator Burton Watson, American sinologists Stephen Owen and Ronald Egan, French sinologist Yves Hervouet, Chinese French scholar Cheng Baoyi, Chinese American scholar Zheng $\mathrm{Su}$ and Chinese translators Wang Rongpei and $\mathrm{Xu}$ Yuanchong among many others, contributed a lot in translating Chinese poetry. Austrian composer Anton von Webern and Gustaw Mahler, French composer Albert Roussel and so on composed music for poems such as Li Bai's and Zhang Ji's, which greatly helped the spreading of poems. China has the tradition of regarding lyrics and poems as one. It's a great pity for Chinese to lose all the music for classic poems. At present, many poems are retuned to help memorize poems and greatly bring out the beauty of musicality of poems. Recently, a few foreign singers, such as Jonny Long, the Danish band, and so on, adapted Chinese popular music lyrics, such as the lyric of Liang Liang, a theme song for a Chinese TV series, Legend, and so on. Chinese translators, such as Wang Hongyin, Zhao Yanchun, Gou Bin and Wen Shilong, translated many Chinese folk songs, especially Northern Shaanxi folk songs, such as What a Jasmine, Romance, Xin Tian You, Zou Xi Kou, and so on. Many of these lyric translations have already walked into the stage and are popular both at home and abroad.

The latter, that is lyric translation from foreign to Chinese, dated from the translation of the scriptures of Christianism and Buddhism. Started from late Qing dynasty, contemporary lyric translation reached prosperity after the establishment of People's Republic of China. Lots of outstanding translators, like Ji Xianlin, Xue Fan, Mao Yukuan, Zhou Feng, Shang Jiaxiang, Deng Yingyi and Lin Caibing, among many others successfully translated foreign lyrics, especially that of Russian, like Auld Lang Syne, Ka Qiu Sha, San Tao Che, Mo Si Ke Jiao Wai De Wan Shang, and so on, which had become symbol of the times, and exerted great influence on generations of Chinese youngsters, the influence on whom was considered no less than that of any classic translations or film works of that time. Nowadays, poets like Xi Chuan, Ma Shifang, Chen Li, Xi $\mathrm{Mi}, \mathrm{Hu}$ Xudong, Chen Zhen, Li Wan, Bao Huiyi and so on translated lyrics of Bob Dylan, an American poet and folk Singer who won the 2016 Nobel Prize.

Whether from Chinese to foreign or from foreign to Chinese, lyric translation greatly promoted cross-culture communication. It constructs a shared world culture of love through a special way of singing. People all over the world have been changing and assimilated by the ideologies and philosophies hide behind different ideas and cultures of songs. At the beginning of twentieth century, to break the silence of English poems, Ezra Pound created imagism by translating Chinese poems, similarly, the translating of excellent foreign songs greatly enriched Chinese music. The combination of Chinese and Western musical instruments and musical theories will boost the progress of music of the whole mankind. The idea of Confucianism, Taoism and Buddhism harbored in Chinese classical poems will complement Western utilitarianism. Nevertheless, apart from lyric translation practices, theoretical research still awaits a long way to reach its maturity. The only existing book on lyric translation theory in China is Xue Fan's Exploration and Practice of Lyric Translation. There were actually a lot of academic dissertations devoted their efforts on theoretical study of lyric translation, and contributed a lot to the development of lyric translation theory, but more in-depth study were needed if it was to become an indispensable branch of translation study. 


\section{THE CHARACTERISTICS OF LYRICS}

Lyric is a special text type that greatly different from other text types. Lyrics have the characteristic of poetics from poetry and musicality from music and rhyme.

Lyrics firstly should be poems. Different from prose, stories and spoken languages, languages of poems should be concise, expressive and full of musicality. For example, The Book of Songs is full of highly condensed words that reflect the then social life. These words we now regard purely as poems, totally neglecting their original category of songs. And there are many vivid and picturesque nouns and verbs in The Book of Songs which are common characteristics of both songs and poems. For instance, with monosyllable prevalent in Zhou Dynasty, in the book more than thirty different monosyllabic nouns were used to describe the concept of "horse" and more than fifty concrete verbs were used to depict the motion of hand and so on. Many of the often-used expression have become idioms that were cited regularly by late-comers [2].

For another example, the Nobel Prize Winner Bob Dylan got the prize mainly for the poetics of the lyrics of his songs. He was said created a new expression of poetics by using traditional American songs [3]. His language are exquisite and elaborate, at the same time touching and expressive, make people's heart ripple each time singing, listening, or even reading. So, undoubtedly great songs are great poems.

Secondly, songs have double musicality, one for melody, the other for rhyme. In other words, lyrics are restricted by both music score outside and rhyme inside. With different characteristic of each language, such as tones of Chinese and stress of English, different methods are used to achieve the rise and fall of music, in other words, the tones of Chinese and stress of English should be forever in direct proportion to the rise and fall of music, otherwise, confusion in meaning would not be avoided. Therefore, apart from considering meaning and form, lyrics should be identical to music scores. The same situation is true to inside rhyme. Chinese and English have different rhyme systems which they should apply to achieve harmony and emotional fluctuation. In Chinese, four tones formed Ping and $\mathrm{Ze}$ in rhyme. Chinese rhyme totally relies on Yunmu (similar to English vowels), and always happens at the last word of a sentence in a song. While English rhyme is free of restriction in place. There is assonant rhyme, consonant rhyme, feminine rhyme, head rhyme, near rhyme, perfect rhyme, and so on. Chinese tend to rhyme in each last word, while English use alternating rhyme scheme, enclosing rhyme scheme, and so on [4]. All roads lead to Rome. Lyrics in different languages are symbols of beautiful music despite different means.

\section{THE SPECIALTIES OF LYRIC TRANSLATION}

It's safe to say that lyric translation is more difficult than other types of translations for the double restrictions of melody and original language. Lyric translator is in fact a lyricist who uses a different kind of language from different cultures to compose a song with original tune and target rhymes. Embedded both in tunes and languages, like painting, calligraphy and other arts, Chinese classical songs can be regarded as inheritance of traditional Chinese philosophy of Confucianism, Taoism and Buddhism and tend to use image to express one's inner appeal. Pursuing the destination of harmony and etiquette, nature and "one", nothingness and perception is a shared theme of Chinese music. Chinese songs call for a combination of feelings and scenes because of the influence of poetry. Descending from religious belief, Western classical songs are closely concerned with one's soul and spirit, and manifest a feeling of divinity and solemnity. And different from Chinese songs which are greatly influenced by Chinese poetry, Western songs affected a lot by Western dramas, which results in its inclination of subjectivity and functionality. Furthermore, Western songs inherited the great philosophical thoughts of Plato, Aristotle and others, reflecting in themselves a great feature of rationality. In ancient times, musical instruments and melodies were by and large born in the need of politics and ideologies. Whereas, today, it is common for music composers to combine foreign musical instruments with native ones and include foreign factors in composing a tune. In translating lyrics, tunes cannot be changed, but one thing should be remembered, that is the fall and rise of translated lyrics should always be in accordance with the original tune and original lyrics [5].

As the soul of a nation, lyrics reflect everyday life, geographical features and emotional feelings of different areas and different peoples, and inevitably reveal different cultures, philosophies, thinking modes and aesthetic features, whose transfer needs extra efforts in translation to achieve balance between two different cultures. If we divide lyric translation into two stages: surface and deep, we call transformation of words, including artistically handling of dialects, implications, rhetoric, rhythms, culture-loaded connotations and so on, surface translation, and successfully retaining the original philosophy, such as the idea of great harmony from Chinese lyrics and enterprising from Western lyrics, deep translation. In other words, surface translation is a skill, which requires translator to be a good commander of two cultures, poetical features, and musical characteristics and so on. While deep translation sublimes into ideological level. Translated lyrics should be sincere enough to be regarded as moral models or soul redeemers for a peace and happy life all over the world [6] For that reason, lyric translation is of great challenge and significance. 
As a result, the first thing for successfully translating a good piece of song is choosing appropriate and haunting words in the target language for each original sentence. The unit of lyric translation should be sentence instead of word, or maybe sometimes it's better to extend to a paragraph. Songs are to express feelings or act for admonishment for good deeds. Words are too split to be the core of any expression. Like other kinds of works, if take the whole piece as unit, translations will become new born babies instead of adopted ones. But songs are restricted by tunes, choosing a right word for a sentence in a lyric will be more difficult than in other kinds of works. In addition, translating a lyric is more difficult than creating a song. Songs can be created by three ways: writing words comes first, producing tunes for the words comes next; composing tunes first, and then write for the tunes; if the composer and writer is one person, it's possible that composing and writing would happen at the same time. Most people choose the first type, because it's easier to compose tunes for existed words. While in translating, one should always bearing in mind that tunes are there ahead, selecting right words is the only thing one can do. Choosing a right word should be firstly based on the tone of the entire song and the meaning of the sentence. Then the delicate historical, cultural, customary, and aesthetic meaning of the word should be considered. Finally, what is a perfect translation for the original text by no means is a perfect choice for a song. Words should be tested by tunes and rhymes. More than often the procedure will happen repeatedly because it's only luck for one to find a word that perfectly fit for the tune at the first time.

To avoid breaking the perfect relation of the proportionable tri-factors of tune, original words and target words in the direction of flowing pitch, sometimes inversion of word order is inevitable. What the inversion of word order means here is different from the change we made in order to adapt to the normal word order that we learned about different languages in translation, such as because of the rule that attributes always happen before nouns in Chinese while except a single word as attribute, phrases or sentences as attributes in English should be put after nouns, when we translate a sentence attribute in English lyric into Chinese, we need change the place or even change part of speech to make the sentence smooth. The inversion of word order here will result in abnormal word order which should be regarded as incorrect and should be avoided in any writing or translating. But in lyric translation or writing words for a tune one cannot but do it to fit for the tune or rhyme if it will not hinder understanding. In general, despite different word orders of two languages and the consideration of tunes and rhymes, words that the author emphasized or in the place of climax should be kept still as possible as one can, such as names of persons or places. And the number of notes, original words and target words should be basically kept alike to assure the same tempo and cadence which are important factors in shaping the overall sentiment of a song.

Secondly, it's wise for one to think comprehensively several times the overall translations to guarantee whether they grasped the spirit, sentiment, and charm of the original song. The situation may happen that each sentence of a song was rendered perfect and the sentences were well connected, in other words, cohesion of the song was achieved, but the song was different a lot from the original in that it changed the original conceptual relations, such as viewpoints, values, aesthetic propensities and so on, in other words, coherence of the song was lost [7]. Therefore, subtle changes are required to complete the final step.

On the contrary, what should be noticed is that the difficulty brought about by the restriction of melody should not be an excuse for limitless freedom in lyric translation. Keeping the original spirit, sentiment and charm at the expense of original meaning and form, that is keep the soul with a totally different body, is not a good translation, for the original cultural flavor which lived in concrete words is totally lost. The new version is at best a new creation but not a translation. Taking the famous Chinese singer Wangfei's song Legend for example, to keep the original meaning Chinese translator Zhao Yanchun's version used more words than the original, thus speeding up the tempo of the translated version, but it's a good try because the original cultural image kept intact, while although the Danish band's version seemed more catching than Zhao's version, it's more like a creation. Reproducing the native ingredients should be regarded as important as recreating the original spirit. The task of translation is to promote communication between different cultures and help understanding each other. The default of important factors in original culture could be tolerated, but the awareness of cultural identity should also be a translator's unfailing obligation.

At last, a simple and good reason for advocating translating lyrics in cross-cultural communication is that lyrics are easier accepted by readers than other types of text. Lyrics are received by way of hearing or singing, which is more relaxed and joyful than reading. Therefore, songs are fit for everyone, whether old or young, literate or illiterate, busy or ease. A beautiful and unforgettable song can lure a foreigner into investigating the original life and culture, which would unconsciously help realize the goal of cultural exchange.

\section{REFERENCES}

[1] Zhao Changjiang (2014). A Study of English Translation of Chinese Cultural Classics in the 19th Century. Tianjin. Niankai University, May.

[2] Wang Xiumei (2015). The Book of Songs. Beijing. Zhonghua Book Company, September.

[3] Bob Dylan, translated by Bao Huiyi etc. (2017). Bob Dylan the Lyrics 1961-2012. Guilin. Guangxi Normal University Press, June.

[4] Xiang Xiyuan (2002). Chinese and Western Music Theory. Beijing. Chinese People's Publishing House, May.

[5] Xue Fan (2002). Exploration and Practice of Lyric Translation. Wuhan. Hubei Education Press, May.

[6] Guan Jianhua (2013). Cultural Perspective of Chinese Music Aesthetic. Nanjing. Nanjing Normal University Press, November.

[7] Mona Baker (2018). In Other Words: A Coursebook on Translation. London and New York. Routledge, March. 